\title{
Estudo sobre o alçamento de vogais médias pretônicas e os itens lexicais*
}

\author{
Maria do Carmo Viegas \\ Universidade Federal de Minas Gerais
}

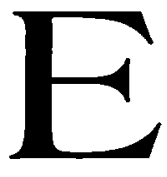

ste trabalho é uma retomada do tema de minha dissertação de mestrado "O alçamento de vogais médias pretônicas: uma abordagem sociolingüística", defendida em 1987, em que

analiso a elevaçào do traço de altura das vogais médias pretônicas (casos como 'mininas', 'cunversa', etc.) na fala de moradores de duas áreas, diferenciadas sócio-economicamente, da regiảo metropolitana de Belo Horizonte.'

Nessa dissertação, além de uma proposta de diferentes regras, uma para o (e) outra para o (o), mostro que há evidências de uma atuação lexical relacionada ao alçamento.

Em Viegas (1987), encontrei essa relação evidenciada em formas como Peru e piru, entre outras. Neste par, temos, hoje, itens com significados diferentes, um item alçado e outro não, mas que tiveram origem no mesmo item (piru veio do topônimo Peru, segundo Cunha, 1982). Se observarmos os pares de homônimos, veremos que o item alçado é aquele cujo uso normalmente é feito em situações mais familiares, ou menos prestigiadas (pirué também

- Este trabalho constitui parte da minha tese de doutorado intitulada "O alçamento de vogais médias pretônicas e os itens lexicais", defendida em agosto de 2001, na UFMG.

' VIEGAS, 1987. p. 2. 
um item considerado chulo). Nas formas em que a vogal média está em oposição distintiva em relação à vogal alta, aqueles itens que têm um uso considerado menos prestigiado socialmente alçam (purção, com significado de "muita quantidade", traz o rótulo brasileirismo em dicionários) e aqueles cujo uso é socialmente considerado mais prestigiado não alçam (Perı é inclusive escrito com letra maiúscula e porção é usado, normalmente, em restaurantes).

Viegas (1987) é um trabalho que reconhece a implementaçào das regras como um processo lexicalmente gradual. No entanto, maiores estudos fizeram-se necessários para entendermos melhor o processo de alçamento.

Outro ponto que motivou a elaboração deste trabalho foi o estudo de Oliveira (1991) que questiona as regras de alçamento propostas em Viegas (1987), indicando que tanto ciroulas como cenoura e cebola têm ambientes semelhantes mas o primeiro item alça e os outros não (assim como simestre e semana). Oliveira propõe que toda mudança sonora se dê por difusão lexical e que:

The earlier victims of a sound change of the form $X \rightarrow Y / Z$ are the words which present the following features (not necessarily in this order):

a) $X$ occurs in a common noun.

b) $Z$ is part of a natural phonetic environment to $Y$.

c) $\mathrm{X}$ is part of a word which occurs in informal speech styles. ${ }^{2}$

Analisando os itens ciroulas, cenoura e cebola, assim como semana e simestre, citados por Oliveira (1991), observamos que são nomes comuns, possiveis em estilo informal e que não possuem contexto para mudança, no entanto, uns alçam e outros não. Ou seja, os itens, ou os traços dos itens citados, não se encaixam na tendência da explicação de Oliveira, assim como cumida e comício, tupete e topado, problema e murcego, acentua e abrivia, perdiz e pirdi, etc. O que observo é que muitos desses itens podem ter sido incorporados com a vogal já alta (tupete, murcego, etc.)

2 OLIVEIRA, 1991. p. 104. 
Desta constatação, houve a necessidade de um estudo histórico mais detalhado dos itens lexicais, pois é necessário fazermos uma análise histórica para, então, fazermos uma análise do resíduo de aplicação da regra, ou seja, itens que possuem contexto e, portanto, poderiam ser atingidos pela regra e não o são, e dos itens que não possuem contexto e que, apesar disso, alçam.

Essas foram as motivações iniciais para este trabalho, cujo objetivo principal é disculir dois modelos teóricos da mudança lingüistica (o neogramático e o difusionista), tendo como ponto de partida o alçamento de vogais médias pretônicas no português falado na região metropolitana de Belo Horizonte. Busco, pois, enquadrar o processo de alçamento no modelo que melhor o descreva e explique.

Pretendo, ao final, responder algumas questões que estão colocadas pelas teorias a respeito da mudança, como:

1) A mudança atinge as palavras abruptamente, ou seja, atinge todas as palavras de uma só vez, conforme diziam os neogramáticos?

Meu objetivo aqui é observar se a afirmaçĩo de Paul (1966) se verifica no caso do alçamento:

(...) na alteração fonética adentro do mesmo dialeto, todos os casos isolados que apresentam as mesmas condições fonéticas sìo tratados da mesma maneira (...) tendo sobrevindo um desdobramento em diversos sons, deve poder explicar-se por uma causa de natureza puramente fonética, como seja a influência de sons próximos, a entoação, a colocaçào das sílabas, etc. (...) o sentido mecânico nào se forma especialmente para cada palavra, mas, sempre que na fala voltam os mesmos elementos, a sua produçio é regulada pelo mesmo sentido mecânico. ${ }^{3}$

2) A mudança atinge o léxico gradualmente, palavra por palavra, como apregoam os seguidores da teoria da difusão lexical?

3 PAUL, 1966. p. 75. 
(...) LD views sound change as being lexically gradual; it is diffusing through morphemes. ${ }^{4}$

Caso o processo seja lexical, que características teriam os primeiros itens a se submeterem ao processo?

Obviamente temos um problema metodológico se depreendermos sons de formas escritas na análise. Assim, se temos a vogal alta na escrita em determinada época, pressupomos que pelo menos em uma variante tivemos a pronúncia de vogal alta; já se temos a vogal média na escrita em determinada época podiamos, ou não, ter a pronúncia de vogal alta em pelo menos uma variante, ou seja, o grau de incerteza é maior.

Tomo, então, a escrita como reveladora da pronúncia, pelo menos no período chamado de ortografia fonética (dos primeiros documentos até o século XVI). O que é certo é que se existe um periodo ortográfico que pode nos dar pistas sobre a pronúncia das palavras, este é o chamado periodo fonético; posto que as convenções ortográficas não estavam bem estabelecidas.

Segundo Naro:

Em suma, há duas tendências evidentes. Até Barreto (1671) o sistema ortográfico não apresentava nenhum problema pois nào havia uma separação notável entre a ortografia e o uso da língua falada. Até o tempo de Feijo (1739), a confusào era tào grande que medidas normativas se fizeram necessárias. Mais ou menos na metade entre os dois extremos opostos (1696), a máxima de Quintiliano ['sic scribendum quomodo sonat.'] foi apropriadamente suprimida e até recentemente nāo se permitiu que ressurgisse."

Obviamente, depreenderem-se sons das palavras escritas não é nada simples, mas essa análise combinada com as análises feitas por estudiosos da história da língua e com a análise dos sons tal qual eles se apresentam hoje forma um quadro que se sustenta mais firmemente. E é dessa forma que se constitui esse trabalho.

+ WANG e LIEN, 1993. p.348.

' NARO, 1973. p.28. 
Da investigaçào histórica de diversos itens, podemos dizer que: - existem itens que não seguem a "lei geral" na passagem do latim ao português;

- existem variações na passagem do latim ao português;

- na maioria dos casos a forma alçada é posterior à não-alçada;

- "(...) a elevação do timbre da pretônica por harmonização vocálica remonta ao século XIII pelo menos e está, certamente, no dialeto padrão no século XVI";"

- alguns itens com grafia de vogal alta (figura, virtude, etc.) representam uma retomada da grafia latina; ${ }^{7}$

- no Brasil as vogais médias pretônicas não seguiram o processo que essas vogais seguiram em Portugal;

- hoje, as vogais altas posteriores são altas c as anteriores correspondem a um "e mudo" em Portugal, de modo geral;

- hoje, no Brasil, a variação [e] [i] e [o] [u] caracteriza, por vezes, diferenças dialetais;

- "A pronúncia brasileira nesse ponto perpetua mais uma vez a pronúncia de Portugal antes das grandes mutaçôes fonéticas do século XVIII."

Fazendo um levantamento de itens com vogal média anterior alçados em Viegas (1987) e acrescentando outros coletados por meio de observaçōes menos sistemáticas, também alçados na região de Belo Horizonte, e analisando a história desses itens (Cunha, 1982; Bluteau, R. 1712-1721 e outros), vimos que se retirássemos os empréstimos (visicula), as possiveis analogias (milhor), os itens que têm na sua origem uma vogal [i] ou que, possivelmente, vieram de uma variação [i] muito cedo detectada no português, ficamos com uma lista que contém hoje, ou conteve algum dia, o ambiente tido como altamente favorecedor ao alçamento, que é a presença de vogal alta seguinte, indicando um processo de harmonização vocálicà.

\footnotetext{
' MATTOS E SILVA, 1991. p. 59-61.

'NARO, 1973. p.35 e WILLIAMS, 1975. p. 54.

TEYSSIER, 1997. p. 101.
} 
Então, como estamos usando o modelo explicativo neogramático, concluímos que o ambiente vogal alta seguinte foi altamente favorecedor ao alçamento do item (midida, mintir, pindurar, etc.). Existem, no entanto, impedimentos para uma conclusão nessa forma, já que existem itens com ambiente vogal alta seguinte que, sistematicamente, não são alçados (Sentido!, adventício, acentuar, etc.). Parece-me que há aí uma outra questão relacionada à formalidade e/ou valoração social e semântico-pragmática do item.

Separando pelo século do primeiro registro (Cunha, 1982) os itens considerados alçáveis, podemos observar melhor o efeito do tempo no processo de alçamento.

e: Itens alçáveis (sem os empréstimos) - século XIII.

Empréstimo: origem não latina
1) aparecia, aparicimento (XV)
3) aprendi
5) cemitério, cymiteiro
7) consentir, consintidor (XIV)
9) depois

11) devia

13) fervido

15) jejum, jajun

17) melhor, milhor

19) messias

21) oferecido

23) pendurar, pendorar

25) pequeno

27) perigo

29) peru (do topônimo)

31) prendi

33) revelia

35) segundo

37) senhor

39) servir

41) testemunho, testimoyo

43) vencido

45) vestir
2) apelido, apelidar (XIV)

4) arcebispo (l. ecles.)

6) conhecia, connocer (XIII)

8) dependumar, dependorar, pendurar

10) derrubar, derrubar

12) ferir

14) gengibre, gingibre (XV)

16) medida, midida

18) mentir

20) nenhum, nengun, nigu (XIV)

22) peclir, pitiçon (XIII)

24) penitência

26) percebido

28) pertencia

30) preguiça, priguiça (XIV)

32) recebi, recybymento

34) seguir

36) segurar

38) sentir

40) tesouro

42) tremido

44) vencliclo 
e. Itens alçáveis (sem empréstimos) - século XIV:
1) abreviar, abriviar (XV)
2) agradescer
3) bexiga (vexiga)
4) defunto
5) desistir
6) feliz
7) mestiço
8) perseguir, persiguir
9) repetir
10) tesoura, tisoyra (XV)
11) travesseiro (traveyseyra)
12) verruga (berruga)

e. Itens alçáveis (sem empréstimos) - século XV:
1) arripiar, arripiado (XVI)
2) digerir, digirir
3) gengiva, gingiva
4) impedir
5) intestino
6) mexido
7) veludo
1) acreditar
3) conseguir
2) cerzir
5) inferir
4) deveras
7) ofendido
6) mexerica
9) pressentir
8) precisa
10) querido

$\underline{e}$ : Itens alçáveis (sem empréstimos) - século XVI:

11) seringa

e. itens alçáveis (sem empréstimos) - século XVII:
1) aperitivo
2) preferir
3) relinchar
1) exigência
3) peludo
2) existir
4) pepino

e. Itens alçáveis (sem empréstimos) - século XVIII:
1) agredir
3) beliscar
2) apreciar
1) decidir
4) besuntar
7) impetigo
6) existir
9) semestre
8) penico

e. itens alçáveis (sem empréstimos) - século XIX:

e. Itens alçáveis (sem empréstimos) - século XX:

1) irrequieto

2) penicilina (via inglês)

3) regredir 
Os itens que chamamos populares, do dia-a-dia, são os primeiros itens a serem alçados, indicando que os primeiros itens a se submeterem a processos como o alçamento são, na maioria, os itens aprendidos.

Observamos ainda que o número de itens alçáveis diminui com o passar do tempo.

Passemos ao estudo das listas dos itens não alçáveis, na região de Belo Horizonte, segundo o meu julgamento, minhas observações e Viegas (1987). Foram selecionados os itens que possuíam ambiente de vogal alta seguinte, visto que é ambiente considerado favorecedor ao processo de alçamento.

Se retirássemos os empréstimos e separássemos os itens por século, teremos:

$\underline{e}$. Itens com ambiente de vogal alta seguinte, não alçáveis $\mathrm{e}$ separados por séculos (sem os empréstimos)

Séc. XIII

1) perdiz

2) petição, pitiçon

Séc. XV

1) cenáculo

\section{Empréstimo: origem não latina}

Séc. XIV

1) cerviz

Sêc. XVI
1) averiguar
2) cerúleo
3) crepitar
4) crepúsculo
5) crespidão
6) perícia
7) netuno

Séc. XVII

\section{Sêc. XVIII}

1) assentir 3) cernir

2) atenuar 4) clandestino

Séc. XIX

1) celícola

Observamos que o número de itens não alçados e com ambiente para tal não é tão grande, no caso do e, indicando que o processo de harmonização vocálica não é tão "excepcional", diferentemente do que nos disse Teyssier (1997):

A mutaçào que nos interessa agora é, no entanto, muito mais importante: ela incide sobre as pretônicas em geral. Tomando-se, por exemplo, palavras como pegar e morar, verifica-se que nelas 
as duas vogais pretônicas sofreram, em Portugal, a mesma mutação que em posição átona final, tendo passado na língua contemporânea, respectivamente, a [ë] e [u]. Como se chega a este ponto?

Cumpre não confundir essa evolução com determinadas interversóes entre e e i de um lado, e entre o e $\underline{\underline{~}}$ de outro, que aparecem, desde época muito remota, em posiçào pretônica.'

Assim, ao que parece, a vogal e passou a $\underline{i}$, através de um processo inicial de harmonização vocálica, atingindo o léxico item a item, ou grupos de itens a grupos de itens. Posteriormente, então, houve a redução do $\underline{i}$, em Portugal.

O processo de harmonia vocálica não é excepcional, ele é lexical. Os itens não alçáveis, são, em geral, mais formais, mais especializados, mais eruditos.

$E$ interessante notarmos que temos itens, com o primeiro registro nos séculos XIII a XVII, que possuem ambiente para o processo de alçamento (perdiz, cerviz, crepísculo, netuno, etc.) e que não foram registrados alçados na amostragem, enquanto outros, nessas condiçōes descritas, foram registrados alçados (cimitério, midida, ninbum, etc.), mostrando-nos a atuação lexical.

Assim como foi feito para o $\underline{e}$, separamos os empréstimos e estamos avaliando a possibilidade de muitos itens terem $o \underline{o}$ somente na grafia e há muito terem a pronúncia [u] em pelo menos uma variedade do português, que acabou constituindo a variedade por nós estudada. Uma possibilidade explicativa da análise é que alguns itens que vieram de vogal alta (gurdura, murcego, musquito, etc.) ou que tiveram um registro com vogal alta no português do Brasil recém descoberto têm a pronúncia de vogal alta hoje, na variação estudada, com base na pronúncia daquela época. Mas, no caso do o, a elevação da vogal média, tendo em vista o ambiente de harmonização vocálica, precisa ser considerada anteriormente, no latim, ou na sua passagem para o português, para que tenhamos maior sistematicidade.

9 TEYSSIER, 1997. p. 74. (Grifo meu) 
No caso do $\underline{o}$, o número de exceções a uma possivel regra é muito maior que no caso do e. Teremos que nos esforçar muito mais se quisermos diminuir o número de exceções, se estamos adotando princípios neogramáticos. E, ainda assim, o número de exceções é grande.

Temos alçados budega, chucalbo, cümer, cümpadre, cünsertar, cusstela, culsteleta, encümendar e tullerar. E os itens culber (s.) $\mathrm{c}$ colber (v.)? Nem com todo esforço neogramático conseguimos uma explicação para o seu alçamento. Estou tentando aqui assumir os princípios neogramáticos, exatamente para mostrar que, mesmo buscando a regularidade do processo, a qualquer custo, não conseguimos dar conta de todos os casos. É o caso de Porluguês (a disciplina), colına, comício, etc. Parece-me que há aqui também a questão da formalidade e/ou valoração social e semânticopragmática do item. Mais uma vez temos evidências de que estamos diante de um processo de difusão lexical, pois o processo atinge alguns itens e não atinge outros.

No caso de $\underline{\underline{0}}$, a extrapolação do ambiente vogal alta seguinte (büdega, bucejar, apüdrecer, etc.) é evidente. Então poderíamos pensar que o ambiente favorecedor deve ser outro. Qual? Consoantes adjacentes? Temos vários itens com a mesma consoante precedente, alçáveis e não-alçáveis (cünsertar, cümer, cüstela, coligir, comicio, contusão, etc.).

Se compararmos alguns itens com o primeiro registro no século XIII e que não alçam (apostila, colına, condição, confirmar; consentir, etc.), com outros alçáveis e com primeiro registro no século XIII (acümpanbar, actustumar, adürmecer, apüdrecer, apruveitar, futrmiga, etc.), observamos que, de modo geral, são os itens passados de geração a geração no meio familiar os primeiros a serem alçados.

Assim, a lista do alçamento decresce com o tempo e com o aumento dos empréstimos. A lista do não-alçamento cresce com o tempo. Uma possibilidade interpretativa é que a mistura de dialetos acirra o estigma e desperta um certo grau de consciência do estigma 
do alçamento, que estava vinculado aos grupos do início da colonização, e que se perpetuou até os dias de hoje.

É comum na literatura ${ }^{11}$ considerar-se o português falado hoje no Brasil, ou em outras ex-colônias cle Portugal, como uma etapa da evolução do português falado em Portugal. Se a pronúncia das pretônicas hoje é uma etapa da evolução do português de Portugal, então o [o], que passou a lu] cle modo geral, em Portugal, atingindo todo o léxico, não o atingiu abruptamente mas item a item, pois a pronúncia [u] no Brasil hoje não cobre todo o léxico.

Segundo Teyssier:

Todas essas variaçôes vocálicas sìo fenômenos antigos. Ocorrem, com muita freqüiência nos textos do século XVI. Não se deve, porém, concluir, em nenhum caso, que elas caracterizam uma evolução do sistema e, em particular, uma passagem cle lel a li] e de [o] a [u]."

Discordando das afirmaçòes de Teyssier, podemos dizer que, no caso da vogal média posterior, os itens que passaram a [u], muito cedo no português, podem indicar o início de um processo que foi atingindo o léxico gradualmente e que culminou com a mutação de [o] a [u], considerada por Teyssier muito mais importante porque incicle sobre as pretônicas em geral. Maia (1986) e Mattos e Silva (1991), diferentemente de Teyssier, também dão ênfase ao processo de harmonia, ou harmonização, vocílica. ${ }^{12}$

Há uma extrapolação do ambiente considerado favorececlor ao processo e há itens com ambiente favorecedor que não alçam, conforme analisamos. Isto é verdadeiro particularmente no caso do $\mathrm{l} /$. Ao que parece, o /o/ teve o seu processo extrapolando os ambientes favorecedores antes do /e/. Então a transformação do [o] em lul foi atingindo o léxico gradualmente, até se completar em Portugal, mas não no Brasil.

${ }^{10}$ NARO, 1973. p. 24 e TEYSSIER, 1997. p. 101.

"TEYSSIER, 1997. p. 75.

12 MAIA, 1986. p. 530-532 c MATTOS E SILVA, 1991. p. 50-61. 
Por volta de 1800, a transformaçăo [o] em lu] está consumada. ${ }^{19}$

Como pudemos observar, os primeiros itens a se submeterem ao processo foram os populares do "patrimônio hereditário". O desprestigio dos portugueses no Brasil, assim como o desprestígio do alçamento, era evidente como nos disse Naro (1973). Ao passo que as palavras eruditas constituem valores, prestígio, e desfavorecem o processo de alçamento.

$\hat{E}$ interessante observarmos que isso aconteceu na região de Belo Horizonte e uma possibilidade explicativa é que isso não tenha acontecido em outras regiões em que não houve uma marcação de estigma para o alçamento, o qual, então, propagou-se para outros itens, inclusive empréstimos. $O$ alçamento não ganhou aí uma marcação de estigma social. Em algumas regiões o alçamento pode ter atingido muitos itens do léxico e em outras nem tanto, dependendo do grau de estigma e marcação que os grupos que se estabeleceram nessas regiões tenham atribuído ao alçamento.

Como seria possível explicar as exceções hoje e, principalmente, nos primeiros séculos do processo, se não houvesse aí uma questão lexical atuando? Alguém poderia dizer: aqueles itens foram todos alçados (perdiz, crepúsculo, apostila, covil, etc.), todos atingidos pelo processo, mas a grafia não revela isto. Essa afirmação é dificil de ser sustentada pois:

$1^{9}$ ) - os estudos da língua não mostram que o processo tenha atingido todo o léxico inicialmente; ao contrário, a variação existente na escrita indica que talvez o processo tenha sido lexicalmente gradual (pela grafia de vogal alta em alguns itens, mas não em todos) e também foneticamente gradual (pela confusão da grafia, ora alta ora média, em um mesmo item, no mesmo texto);

$2^{\circ}$ ) - o português do Brasil - tomado como uma etapa do português de Portugal - é mais um indício de que o léxico não foi atingido abruptamente, pois aqui, como já foi mencionado, alguns itens alçam, outros não;

is TEYSSIER, 1997. p. 75. 
Teyssier (1997) afirma que:

(...) o 'brasileiro' pratica algumas das transformações excepcionais das pretônicas que a língua antiga conhecia: por exemplo: entrar c estar com o intrar e istar, ou menino c costume pronunciados mininu e custumi."

Esta afirmação indica, pelo uso do termo "excepcional", que o caráter do processo não era (e não é) uniforme em termos lexicais.

O alçamento se iniciou nos itens transmitidos, populares, cotidianos, menos marcados, posteriormente adquiriu certo grau de estigma social e o processo passou a atuar nos itens mais pejorativos, palavrões, itens jocosos, irônicos.

$\hat{E}$ interessante observar aqui que recortes diferentes na amostragem dos dados podem nos levar a explicações diferentes do processo. Em Viegas (1987) temos uma amostragem baseada em dados colhidos em entrevistas gravadas em determinadas comunidades de fala e podemos observar alguma regularidade que subjaz ao processo, acrescida de exceçôes. Esta regularidade pode estar comprometida ou tendenciada se o número de ocorrências de determinado item for muito grande. Mas, por outro lado, se analisarmos itens lexicais isolados, poderíamos dizer que a questão é puramente lexical, pois se compararmos itens com ambientes semelhantes, um alça e o outro não. E estamos vendo que a questão pode ser interpretada diferentemente: existem ambientes favorecedores e restrições lexicais relacionadas ao grau de familiaridade do item e à valoração social do item.

A regra de harmonização proposta para o/e/ em Viegas (1987) parece se encaixar bem nos estudos históricos como uma tendência. Já a regra proposta em Viegas (1987) para o /o/ - levantamento devido às consoantes adjacentes - é muito abrangente e dificilmente encontramos itens que aí nào se enquadram, ou seja, atinge quase todo o léxico (como ocorreu em Portugal).

14 TEYSSIER, 1997. p. 101. 
Labov ${ }^{15}$ nos diz que a distinção entre os homônimos (Sentido! $\mathrm{x}$ sintido; purção $\mathrm{x}$ porção; Peru $\mathrm{x}$ piru) ocorre para se evitarem os malentendidos. Para ele esta distinção não poderia ser consciente porque esta escolha demandaria tempo e a escolha entre um item e outro tem que ser rápida no momento da comunicação. No caso do alçamento, a clistinção entre os homônimos não é aleatória, como era de se esperar se fosse só para se evitarem os malentendiclos. Os itens alçados são sempre os menos prestigiados e os não alçados são sempre os mais prestigiados, como vimos. Esta é uma marcação estabelecida socialmente. Se a distinção entre os homônimos não é consciente no momento da comunicação, isto não implica em não haver ou ter havido uma marcação determinada socialmente nos itens lexicais. No caso do alçamento, por exemplo, a opção pelo alçamento recai, sistematicamente, nos itens populares, de uso menos prestigiado. Há uma marcação social, estabelecida historicamente, que estigmatiza o processo de alçamento, ${ }^{16} \mathrm{e} \mathrm{também}$ há uma marcação nos itens usados em situações consideradas menos prestigiadas. E a escollha não consciente não implica em não perpassar sentidos já marcados historicamente.

Assim, poderíamos até manter o fator regularidade dos neogramáticos como sendo consistente com um processo do tipo do alçamento (pelo menos no caso do e $)$, mas não o fato de a mudança atingir o léxico abruptamente, sem exceções. A mudança é lexical e não está condicionada por fatores fonéticos apenas.

${ }^{15}$ LABOV, 1994. p. 604.

16. “Há também um fator social independente a considerar no caso do Brasil. Contrariamente à situaçăo encontrada em outras linguas exportadas ao novo mundo, no português a PRONÚNCIA européia (oposta à sintaxe ou outras partes da gramática) parece nunca ter constituído um padrào de prestígio (...) e em épocas recentes os brasileiros tendem a considerar o sotaque europeu engraçado e até hilariante. Esta atitude é evidentemente mais antiga do que se poderia esperar; testemunha disso são os papéis bem pouco prestigiosos atribuídos ao 'português' em peças populares em ambos os lados do oceano desde o século XVI." (NARO, 1973. p. 45) 
Devemos ter bastante critério quando utilizarmos o "princípio uniformitário", ou seja, "o uso do presente para explicar o passado", pois as marcações do presente podem não ser exatamente as mesmas marcaçōes estabelecidas em todo o processo. No passado, podemos ter julgamentos, valoraçōes sociais diferentes das do presente. O princípio uniformitário se aplica à estrutura lingüística.

Labov (1994) se utiliza para a explicação dos processos de mudança da teoria da Fonologia Lexical, que postula dois tipos de regras, lexicais e pós-lexicais (que não admitem "exceçōes"). O alçamento ("vowel shifts in place of articulation") estaria enquadrado como um processo de mudança sonora regular (oposto à difusão lexical), segundo Labov.

No caso do alçamento de vogais médias pretônicas no dialeto da região de Belo Horizonte, hoje, se formos estabelecer regras, estas parecem ter exceções (mürango, símestre), parecem ser sensiveis à fronteira de morfena (renascimento, co-autor), parecem ser ciclicas (cunhbicia, piquininininbo), ou seja, têm caracteristicas das regras lexicais.

Em Labov (1994) há uma descriçào dos processos de mudança levanclo-se em conta os fatores internos; no entanto observamos que fatores considerados externos podem influenciar a reestruturação do item lexical, conforme a interpretação que damos no decorrer deste trabalho.

Argumenta Labov (1994) que:

Regular sound change is the result of a gradual transformation of a single phonetic feature of a phoneme in a continuous phonetic space. It is characteristic of the initial stages of a change that develops within a linguistic system, without lexical or grammatical conditioning or any degree of social awareness ('change from below ). Lexical diffusion is the result of the abrupt substituon of one phoneme for another in words that contain that phoneme. The older and newer forms of the word will usually differ by several phonetic features. 
This process is most characteristic of the late stages of an internal change that has been differentiated by lexical and gramatical conditioning or has developed a high degree of social awareness or of borrowings from other systems ('change from above'). 1"

Diferentemente de Labov, penso que o modelo neogramático e o difusionista não diferem na questão da regularidade. Eles diferem na maneira como as exceções são tratadas nos dois modelos. ${ }^{18}$

A questão que se coloca para a resolução de Labov é: qual é e como se estabelece a relação das regras (lexicais e pós-lexicais) com o uso efetivo e o grau de consciência social do processo?

Labov coloca as regras lexicais como foneticamente abruptas - a forma nova e a forma antiga diferindo em vários traços fonéticos - numa fase tardia de um processo. Nem sempre o processo com implementação lexical é foneticamente abrupto. ${ }^{19}$ Kiparsky (1995) critica a caracterização do número de traços fonéticos para a diferenciação das regras propostas por Labov (1994). Observamos que também nos estágios iniciais, não só nas etapas tardias, clo processo de alçamento a implementação é lexical, conforme os estudos históricos. Nas etapas iniciais, existem itens que escapam à sistematização: não foram encontrados alçados quando teriam ambiente para tal (covil, por exemplo).

Devemos nos perguntar: por que as regras lexicais possuem "exceções" e as regras pós-lexicais não? O que isso significa? Que tipo de item constitui "exceção" à regra lexical? Esses itens têm algo em comum?

Também na reformulação de Kiparsky (1995), o processo de alçamento não se enquadra. Argumenta o autor que a difusão lexical se comporta em todo aspecto como a analogia lexical. Este seria um processo foneticamente abrupto, o que, mais uma vez, não se

\footnotetext{
17 LABOV, 1994. p. 542. (Grifo meu)

"N WANG C LIEN, 1993. p. 348.

1) WANG e LIEN, 1993. p. 348.
} 
enquadra nas descrições históricas do fenômeno do alçamento, pois o processo de alçamento parece ter sido foneticamente gradual de acordo com Naro (1973) ${ }^{20} \mathrm{e}$, portanto, nĩo poderia ser implementado por difusão lexical, se difusĩo lexical fosse analogia lexical.

Qual é o conceito de léxico que sustenta uma melhor descrição e explicaçĩo do processo?

Não encontrei evidências a respeito de a implementação lexical estar presente nas regras lexicais apenas. Assim, concordo com Phillips (1998) quando afirma que a implementaçào das mudanças é sempre lexical (quer nas etapas iniciais de um processo, quer nas finais).

Adoto um conccito de léxico "conexionista", ou melhor, um conceito "network" de léxico, conforme Bybee (1995):

A major difference between this model, which 1 will call the netuork model, and structuralist model containing rules is that actual usage in terms of both type and token frequenty plays an important role in establishing and maintaining representation.

(...)

Words entered in the lexicon have varying degrees of lexical strenght, due primarily to their token frequency.

(...)

Words entered in the lexicon are related to other words via sets of lexical connections between identical and similar phonological and semantic features.

The data cited here, and the arguments given, support a functionalist conception of the lexicon, as an store of words and phrases that is highly affected by actual language use..."

20 "A natureza fonética exata das vogais médias é então problemática, mas at observaçào de Gonçalves Viana sugere uma tendência para um leve fechamento. Se isto ć correto, então o $\underline{Q}$ distinguir-se-ia do $\underline{\|}$ mais pelo arredondamento do que pela altura da língua, e, por conseguinte, seria natural esperar que os gramáticos se fixassem no primeiro - como eles de fato o fizeram. Parece, então, que os pares $[o, u],[e$, il eram muito semelhantes foneticamente." (NARO, 1973. p.14)

21 BYBEE, 1995. p. 428-430. 
Temos que reconhecer a influência da valoração social do item nesse processo. Essa influência tem uma direção e um sentido, é uma marcação sistemática que atinge a representação do item lexical como, por exemplo, piru. Não podemos continuar colocando o que não parece regular à parte, como se não fizesse parte de um mesmo processo de mudança.

Um conceito de léxico tal como proposto em Bybee (1995) enquadra bem o processo, postulando a relação do léxico e seu uso. Analisando os casos de alçamento, não podemos falar que:

Therefore our efforts to change language consciously must be confined to higher-level stylistic options: the selection of words, and the construction of phrase and sentences within a narrowly limited set of choices. ${ }^{22}$

Nem podemos dizer que:

All sociolinguistic studies show that conscious choices in language are limited to surface forms and rarely reach the level where systematic linguistic change is operating. ${ }^{23}$

Itens como pilinbo (por pelinbo), piscucinbo (por pescocinbo) refletem hoje o mesmo processo que se passou com piru ou cunserto e que são hoje itens reestruturados.

Não podemos ainda concordar com:

...functional effects are primarily the consequences of linguistic choices rather than the causes of them. ${ }^{24}$

Em "pilinho", "piscucinho" pudemos ver que é a veiculação de um sentido pejorativo ou desprestigiado que causa a alteração de [e] para [i].

Não encontrei evidências da afirmação de Kiparsky cle que a "exceptionlessness hypothesis is correct for changes that originates

22 LABOV, 1994. p. 604.

${ }^{23}$ LABOV, 1994. p. 604.

${ }^{24}$ LABOV, 1994. p. 601-602. 
as phonetic implementation rules", ${ }^{25}$ pois a implementação é sempre lexical. Em etapas iniciais, em que não há uma marcaçaio social para mudança, os itens menos marcados serào os primeiros a "adotar" a mudança, que pode se espalhar pelo léxico, ou não. Nessas ctapas iniciais de processos como o alçamento, a estrutura lingüística atua mas também os itens lexicais, restringindo a atuação do processo. Não podemos concordar com:

(...) tendo sobrevindo um desdobramento em diversos sons, deve poder explicar-se por uma causa de natureza puramente fonética, como seja a influência de sons próximos, a entoaçào, a colocaçào das sílabas, etc. (...) o sentido mecînico nào se forma especialmente para cada palavra, mas, sempre que na fala voltam os mesmos elementos, a sua produçào é regulada pelo mesmo sentido mecânico. ${ }^{26}$

E optamos pelo modelo difusionista tal como Wang e Lien (1993):

In our framework one important addition to the concept of actuation as delimited in (Chen and Wang, 1975) is the thesis that sound change can be triggered system-externally by language contact as well as internally by the constraint of physiological, acoustic and conceptual factors. ${ }^{27}$

Poderíamos perguntar forma é sentido: Se entendermos sentido como "valor apreciativo" como em Bakhtin (1976), então, a resposta é afirmativa. Assim, forma é funçio. Função de marcar a identidade de um grupo social nas mudanças "from below" nos termos de Labov (1994) e função de estabelecer marcaçào de prestígio ou de estigma nas mudanças mais marcadas ("from above").

É o sentido que causa, ou desencadeia, a mudança? Mais uma vez se entendermos sentido como "valor apreciativo" a resposta é sim. O sentido atua motivando a mudança ("piru") ou restringindo-

\footnotetext{
${ }^{29}$ KIPARSKY, 1995. p. 185

2t PAUL, 1966. p. 75.

27 WANG C LIEN, 1993. p. 382-383.
} 
a ("Português", disciplina) e, nas mudanças "from below", a marcação da identidade do grupo social motiva a mudança, que atinge os itens mais familiares primeiro (divia, sirvir).

A noção de que há uma "decadência lingüística", vulgarmente associada à mudança lingüística, pode decorrer da valoração social dada às mudanças que se iniciam "from below", atingindo os itens familiares primeiro.

A análise dos textos corrobora afirmações feitas na análise da história dos itens. Para análise de textos selecionei alguns textos:

a) datados de 1547 a 1567, extraídos das "Cartas do Brasil e mais escritos de P. Manuel da Nóbrega";

b) dos séculos XIII e XIV, publicados em Maia (1986) e classificados como portugueses;

c) do século XII ao XIII, apresentados na Antologia de textos medievais, de Tavares (1961).

Comparando os dados dos textos dos séculos XIII e XIV com os dados dos textos do século XVI, podemos dizer que:

- no caso do $\underline{\text { : }}$

- o item igreja, que nos dados dos séculos XIII e XIV variava, não varia mais, no século XVI, na amostragem.

- o item pior não ocorreu variando no século XVI.

- itens em en inicial ocorreram variando no século XVI, o que não ocorreu antes, na amostragem.

- itens em es inicial ocorreram com a forma is ou $\underline{\mathbf{s}}$ desde o século XIII, ou seja, a elevação do e em es parece ser anterior à elevação do $\underline{\text { e }} \mathrm{em}$ en.

- nomes próprios ocorrem ora com a vogal pretônica alta ora média.

- itens seguidos de vogal alta ora ocorrem com a vogal média, ora com a vogal alta.

- itens que têm a grafia e hoje e que ocorreram no levantamento dos séculos XIII, XIV ou XVI com a vogal i, geralmente, possuem vogal alta seguinte ou estão em sílaba es/en inicial. 
- no caso do o:

- nomes próprios ocorreram ora com $\underline{\mathrm{g}}$, ora $\operatorname{com} \underline{\mathrm{u}}$ : Nugueira, Nogucira, Purtugal, Portugal.

- itens com ambiente vogal alta seguinte ora ocorreram com o, ora com $\underline{\mathrm{u}}$ : cumprido, custume, furtuna.

- o item mulber ocorre ora com $\underline{u}$, ora com $\underline{\text { o. }}$

- itens que ocorreram com o e que hoje são grafados com u quase sempre possuíam vogal alta seguinte: sotileza.

- o item /ordão ocorreu na forma Jurdaam.

- o item governador ocorreu na forma guovernador.

Se acrescentássemos os dados de Tavares (1961), poderíamos dizer que a elevação do o extrapola o ambiente vogal alta seguinte, já que o item coberla ocorre com $\underline{\mathrm{u}}$ e o item /ordão ocorre com $\underline{\mathrm{u}}$.

No caso do e, também notamos a extrapolação do ambiente vogal alta seguinte: os itens melbor, senbor e Geraldo ocorreram com a vogal alta.

Tudo isso sugere que há aí uma questão relacionada ao item lexical.

A metodologia básica deste trabalho consistiu em tomar alguns itens considerados quase sempre alçados e outros não alçados, levantados em Viegas (1987), e acrescentar outros, utilizando-me da minha intuição de falante residente na região de Belo Horizonte desde o nascimento e observaçōes menos sistemáticas para, então, partir para a pesquisa histórica desses itens, separando os empréstimos. Analisei, ainda, ocorrências de vários itens em textos dos séculos XIII e XIV e textos do século XVI.

Fiz novamente o levantamento $\mathrm{e}$ a análise de vários itens coletados na região metropolitana de Belo Horizonte, tentando confirmar al realizaçaio de alguns itens e tentando depreender valores associados ao alçamento e ao uso dos itens.

Para a obtenção dos dados do português contemporâneo falado na região de Belo Horizonte, foram observadas as seguintes etapas:

a) seleçĩo dos bairros Barreiro e Colégio Batista (levando em conta a "social network", conforme Milroy (1987)); 
b) seleção dos informantes (16);

c) seleção dos itens;

d) confecção dos testes.

Posteriormente, foi feita a seleçào de programas de rádio e TV, que foram utilizados como forma de elicitação de dados. Obviamente, os dados da mídia não são equivalentes aos da fala natural, mas servem para confirmarmos hipóteses. No caso em questão, se um item é freqüentemente alçado na mídia, indica que, na fala natural, ele também tenderá a sê-lo.

Confirmamos, com dados do português contemporâneo, as minhas observações menos sistemáticas e a minha intuição, que relacionavam o alçamento ao desprestígio do item, ou à "intimidade" com o item, nos pares de homônimos.

$\mathrm{Na}$ coleta de dados em programas de rádio e TV, os itens encontrados alçados foram geralmente itens familiares do "patrimônio hereditário", como diria Teyssier (1997), se comparássemos com os itens não alçados.

Concluindo, tentando utilizar-me da terminologia de Labov (1994), poderíamos esquematizar a implementação dos processos de mudança sonora, salientando que existe, na realidade, uma gradação entre processos "from below" e "from above":

\section{I - Processos que se iniciam "from below":}

ETAPAS INICIAIS: "não-murcas evidentes" nos itens familiares: permitem a atuaçào do processo até atingir os mais marcados.

ETAPAS POSTERIORES:

(se o processo tornoul-se estigmatizado ("from above")) a) marcas despretigiosas: motivam a atuaçào do processo;

b) marcas de prestígio: inibem a atuaçào do processo.

II - Processos que se iniciam "from above":

ETAPAS INICIAIS: a) marcas de prestígio: motivam a atuação do processo;

b) marcas de desprestígio: inibem a atuação do processo.

ETAPAS POSTERIORES: "não-marcas evidentes" nos itens: permitem a attuaçĩo do processo. 


\section{Referências Bibliográficas}

BAKHTIN, Mikhail (VOLOCHINOV). Marxismo e filosofia da linguagem. 3. ed. Trad. Michel Lahud c Yara Frateschi Vieira. Sìo Paulo: HUCITEC, 1986.

BLUTEAU, D. Rafael de. Vocabulario portuguez e latino. Coimbra: Collegio das Artes da Cia de Jesu, (1712-1721). (8 volumes, 2 tomos cada).

BYBEE, Joan. Regular morfology and the Lexicon. Language and cognitive processes, U.K., Erlbaum, 10 (5), p. 425-455, 1995.

CARTAS do Brasil e mais Escrilos do P. Manucl da Nóbrega - Introdução Notzas Histórias e Críticas: Serafim Leite S. I. Belo Horizonte: Itatiaia, 2000. Ediçâo fac-similar comemorativa dos 500 anos da Descoberta do Brasil (Coimbra por ordem da Universidade, 1955).

CUNHA, Antônio Geraldo da. Diciontírio etimológico nova fronteira da língtıa portuguesa. Rio de Janeiro: Nova Fronteira, 1982.

KIPARSKY, P. The Phonological Basis of Sound Change. In: The Handbook of phonological theory. Cambridge, Mass.: MIT Press, 1995.

LABOV, W. Principles of Linguislic Change. internal factors. Oxford: Black Well, 1994. Vol. 1.

MAIA, Clarinda. História do galego-português - Estudo lingüístico da Galiza e do Noroeste de Portugal desde o século XIII ao século XVI (com referência à situação do galego moderno). Coimbra: I.N.J.C., Fundaçào Calouste Gulbenkian, 1986.

MATTOS E SILVA, Rosa. O português arcaico: fonologia. São Paulo/Bahia: Contexto/UFBA, 1991.

MICHAËLLIS DE VASCONCELOS, C. Glossírio do Cancioneiro da $A j u d a$. Revista Lusilana, Lisbon, 23, 1920.

MILROY, L. Language and Social Netuorks. Oxford: Black Well, 1987.

NARO, Anthony H. Estudos diacrônicos. Petrópolis: Vozes, 1973.

OLIVEIRA, Marco Antônio de. The neogrammarian controversy revisited. International Journal of the Sociology of Language, Berlin, v.89, 1991.

PAUL, H. Princípios fulıdamentais da bistória da lingua. Lisboa: Fundação Calouste Gulbenkian, 1966.

PHILLIPS, Betty S. Lexical Diffusion is nol lexical analogy. Word, 49 (3), p. 369-381, 1998. 
TAVARES, José Pereira. Antologia de textos medievais - seleçào, introduçào e notas. 2. ed. Lisboa: Livraria Sá da Costa ed., 1961.

TEYSSIER, Paul. História da lingua portuguesa. Trad. Celso Cunha. Sào Paulo: Martins Fontes, 1997.

VIEGAS, Maria do Carmo. Alçamento de vogais médias pretônicas: uma abordagem sociolingüística. Belo Horizonte: FALE/UFMG, 1987. (Dissenação de Mestrado em Estudos Lingüísticos)

VIEGAS, Maria do Carmo. O alçamento das vogais médias pretônicase os itens lexicais. Belo Horizonte: FALE/UFMG, 2001. (Tese de Doutorado em Estudos Lingüísticos).

WANG, W.S.-Y e LIEN, C. Bidirectional diffusion in sound change. In: Historical Linguistics: problems and perspectives. Londres: Longman, 1993.

WILLIAMS, Edwin B. Do latim ao portıguês; fonologia e morfologia históricas da Língua Portuguesa. Trad. Antônio Houaiss. 3. ed. Rio de Janeiro: Tempo Brasileiro, 1975. 


\section{Resumo}

O objetivo principal cleste trabalho é discutir clois modelos teóricos da mudança lingüistica, o modelo neogramaitico e o moclelo difusionist:a, tendo como ponto de partida a análise do processo de alçamento (ou alteamento) de vogais médias pretônicas no português falado na região metropolitana de Belo Horizonte.

Observei que alguns itens lexicais que foram consiclerados alçados na literatura não deveriam ser assim considerados, pois poderiam ter siclo incorporados ao léxico português com a vogal já alta. Observei ainda que o processo de alçamento é bastante regular nas suas etapas iniciais. Esta afirmaçio nào exclui a seletividade lexical, que foi evidenciada $\mathrm{em}$ várias etapas do processo de alçamento. Os primeiros itens atingidos pelo processo foram os itens transniticlos, mais familiares, usados no dia-a-dia, com ambiente de harmonizaçło vocálica, mais nitidamente caracterizado no caso do /e/. Posteriomente o processo adquiriu estigma, associado aos grupos sociais que o utilizavam. O alçamento foi usado indicando desprestigio, atribuindo valor pejorativo, e os itens usados alçados foram dessa maneira reestruturados (vide o número enorme de itens chulos alçados). Ainda hoje, observamos o alçamento de itens quue normalmente nito sio alçados quando se quer marcar estes itens pejorativamente.

Adoto o conceito de léxico "conexionista" conforme proposto por Bybee (1995). Neste moclelo de léxico eståo previstos vírios tipos de processos (assimilaçào, dissimilação, etc.) e estai configurada a relação desses processos com o léxico e o seu uso. Opto, portanto, pelo modelo difusionista de mudinça lingüistica por ser o que descreve e explica melhor os dados aqui levantados.

\section{Abstract}

The main purpose of this paper is to make cvident that many lexical items of the portuguese language cannot be seen as exceptions to the pretonic mid vowels raising rules as they have been considered and that through the residuc analysis the remaining exceptions bring out the need of understanding the linguistic change processes as being implemented by lexical diffusion. 